\title{
Improved Algorithm for Efficient and Realistic Creep Analysis of Large Creep-Sensitive Concrete Structures
}

\author{
by Qiang Yu, Zdeněk P. Bažant, and Roman Wendner
}

\begin{abstract}
Recent compilation of data on numerous large-span prestressed segmentally erected box girder bridges revealed gross underestimation of their multi-decade deflections. The main cause has been identified as incorrect and obsolete creep prediction models in various existing standard recommendations and is being addressed in a separate study. However, previous analyses of the excessive deflections of the Koror-Babeldaob (KB) Bridge in Palau and of four Japanese bridges have shown that a more accurate method of multi-decade creep analysis is required. The objective of this paper is to provide a systematic and comprehensive presentation, appropriate not only for bridges but also for any large creepsensitive structure. For each time step, the solution is reduced to an elastic structural analysis with generally orthotropic elastic moduli and eigenstrains. This analysis should normally be threedimensional (3-D). It can be accomplished with a commercial finite element code such as ABAQUS. Based on the Kelvin chain model, the integral-type creep law is converted to a rate-type form with internal variables, which account for the previous history. For time steps short enough to render aging during each step to be negligible, a unique continuous retardation spectrum for each step is obtained by Laplace transform inversion using simple Widder's formula. Discretization of the spectrum then yields the current Kelvin chain moduli. The rate-type creep analysis is computationally more efficient than the classical integral-type analysis. More importantly, though, it makes it possible to take into account the evolution of various inelastic and nonlinear phenomena such as tensile cracking, cyclic creep, and stress relaxation in prestressing tendons at variable strain, as well as the effects of humidity and temperature variations, and the effect of wall thickness variation on drying creep and shrinkage. Finally, the advantages compared to the existing commercial programs, based on step-by-step integration of memory integrals, are pointed out and illustrated by a simple example.
\end{abstract}

Keywords: aging; bridge deflections; commercial programs; continuous retardation spectrum; cracking; creep and shrinkage; cyclic creep; Kelvin chain model; rate-type algorithm; steel relaxation; three-dimensional analysis; variable environment.

\section{INTRODUCTION}

The severity of the effects of multi-decade creep of concrete has long been underestimated. In 2008, however, the release of detailed technical data on the Koror-Babeldaob (KB) Bridge in Palau, which collapsed in $1996^{1,2}$ as a result of a retrofit, provided a wakeup call. When built in 1977, this prestressed segmentally erected box girder had the worldrecord span of $241 \mathrm{~m}$ (791 ft). Within 18 years, its midspan deflection (compared to the design camber) reached $1.61 \mathrm{~m}$ $(5.3 \mathrm{ft})$, which was approximately three times larger than the deflection calculated in design. ${ }^{3}$ The 18 -year prestress loss was measured to be approximately $50 \%$ (as an average of nine readings), which was more than the double of the normally predicted $\operatorname{loss}^{4,5}$ (refer to Fig. 1).

Thanks to other data released in 2008 by Shimizu Construction, Tokyo, similar underestimations of long-term creep effects were also documented for four large segmentally erected box girders in Japan. ${ }^{3,6,7}$ A subsequent search of data on segmentally erected prestressed box girder bridges, undertaken under the auspices of the recently established RILEM Committee TC-MDC (Multi-Decade Creep), led to a list of 69 large spans (in 10 countries) that suffered grossly excessive long-time deflections. ${ }^{8-10}$ It is likely that many more cases of excessive deflections exist worldwide. Clearly, the problem is widespread and its cause must be systematic.

Analyses of the data on the KB Bridge and the Japanese bridges $^{3,6,7}$ with Model B3 (calibrated by multi-decade laboratory tests ${ }^{11-13}$ ) showed that the main causes of the gross underestimation are twofold:

1. Incorrect and obsolete material models for concrete creep surviving in standard design recommendations of ACI, CEB-fib, and other engineering societies; and

2. An oversimplified method of creep structural analysis.

The former is being addressed in a separate study. ${ }^{6-8}$ This article will focus attention on the latter. Assembling previously published results, it will give a comprehensive presentation of the method of multi-decade creep analysis, which can use a general-purpose finite element code such as ABAQUS and has led to excellent agreement with the observations on the KB Bridge and four Japanese bridges.

For the purpose of creep analysis, the prestressed concrete box girders have traditionally been analyzed as one-dimensional (1-D) beams, sometimes using, for the top slab, approximate correction formulas for the shear lag. ${ }^{14-16}$ Such analysis, however, still popular in commercial design software, can have large errors, mainly for two reasons:

1. It cannot realistically capture the shear lag effects, which are not only elastic but also aging viscoelastic, occur not only in the top slab but also in the vertical walls and the bottom slab, and are caused by both the vertical shear forces at the piers and by the concentrated loads from tendon anchors; and

2. It cannot account for the differences in drying creep properties and in shrinkage caused by the differences in the drying rates of slabs, resulting from different thicknesses and environmental exposure.

Properly, the box girders should be analyzed as thick shells, for which a three-dimensional (3-D) finite element analysis is necessary. Such analysis is, of course, also necessary for other creep-sensitive structures such as supertall buildings.

ACI Structural Journal, V. 109, No. 5, September-October 2012

MS No. S-2010-366.R2 received September 13, 2011, and reviewed under Institute publication policies. Copyright (C) 2012, American Concrete Institute. All rights reserved, including the making of copies unless permission is obtained from the copyright proprietors. Pertinent discussion including author's closure, if any, will be published in the July-August 2013 ACI Structural Journal if the discussion is received by March 1, 2013 
Qiang Yu is an Assistant Professor in the Department of Civil and Environmental Engineering at the University of Pittsburgh, Pittsburgh, PA. He was formerly a Research Assistant Professor at Northwestern University, Evanston, IL. He is a member of ACI Committee 209, Creep and Shrinkage in Concrete, and Joint ACI-ASCE Committees 445, Shear and Torsion, and 446, Fracture Mechanics of Concrete. His research interests include mechanical properties and long-term performance of concrete and other engineering materials.

ACI Honorary Member Zdeněk P. Bažant is the McCormick Institute Professor and W.P. Murphy Professor of civil and mechanical engineering and materials science at Northwestern University. A member of the National Academy of Sciences and the National Academy of Engineering, he is the founding Past Chair and a member of Joint ACI-ASCE Committee 446, Fracture Mechanics of Concrete. He is also a member of ACI Committees 209, Creep and Shrinkage in Concrete; 348, Structural Reliability and Safety; and Joint ACI-ASCE Committees 334, Concrete Shell Design and Construction; 445, Shear and Torsion; and 447, Finite Element Analysis of Reinforced Concrete Structures. He is a licensed structural engineer in Illinois.

Roman Wendner is a Postdoctoral Research Fellow at the University of Natural Resources and Life Science Vienna, Austria, where he also received his PhD in 2009. Since April 2011, he has been officially on leave to conduct research at Northwestern University supported by an Erwin Schrödinger Scholarship. His research interests include the reliability and lifetime assessment/prognosis of engineering structures with special focus on system identification, nonlinear fracture mechanics, and the modeling of long-term processes.

\section{RESEARCH SIGNIFICANCE}

Achieving sustainability of built environment requires that the design of large bridges, as well as other large creep-sensitive structures such as super-tall concrete buildings or largespan shells, would ensure a lifetime of at least 100 years. Excessive creep deflections and prestress losses shorten the life span to approximately 20 to 40 years. The result is an enormous economic loss. Whereas in most cases excessive creep deflections will not cause collapse per se, they may provoke a retrofit with additional prestressing, which can be risky and may lead to collapse with a loss of life, as witnessed in Palau. ${ }^{2,17,18}$ Therefore, a realistic method of multi-decade creep structural analysis is one essential part of sustainable design.

A realistic method is also needed for reanalyses of some recently completed structures. Excessive deflections produce cracking and, even if a retrofit is successful, the cracking does not heal. Thus, should reanalysis show future excessive deflections to be likely, a retrofit could be performed before any damage develops.

\section{REASONS FOR COUPLING FINITE ELEMENT ANALYSIS WITH RATE-TYPE CREEP FORMULATION}

Concrete creep at constant stress and in constant environment is characterized by the compliance function $J\left(t, t^{\prime}\right)$, which represents the strain at time $t$ caused by a unit sustained uniaxial stress applied at age $t^{\prime}$. Generalization for time-variable stress $\sigma(t)$ is obtained by applying the principle of superposition in time, which yields a linearly viscoelastic stress-strain relation in the form of a Volterra integral equation with a kernel which, because of chemical aging, is not of convolution type. According to this classical formulation, the evolution of deflections, nodal displacements, or statically indeterminate internal forces is characterized by a system of linear Volterra integral equations.

However, the integral-type approach to aging viscoelasticity is too complicated and computationally inefficient for larger structures. More seriously, it is also unrealistic because many influencing phenomena can be taken into account only with a rate-type, rather than integral-type, formulation. Although the history integrals of aging viscoelasticity are a valuable pedagogical tool for the conceptual understanding of various kinds of viscoelastic effects in structures, especially the long-time stress redistributions, in practice they are adequate only for crude preliminary estimates and illustrative calculations of simple beam or frame structures.
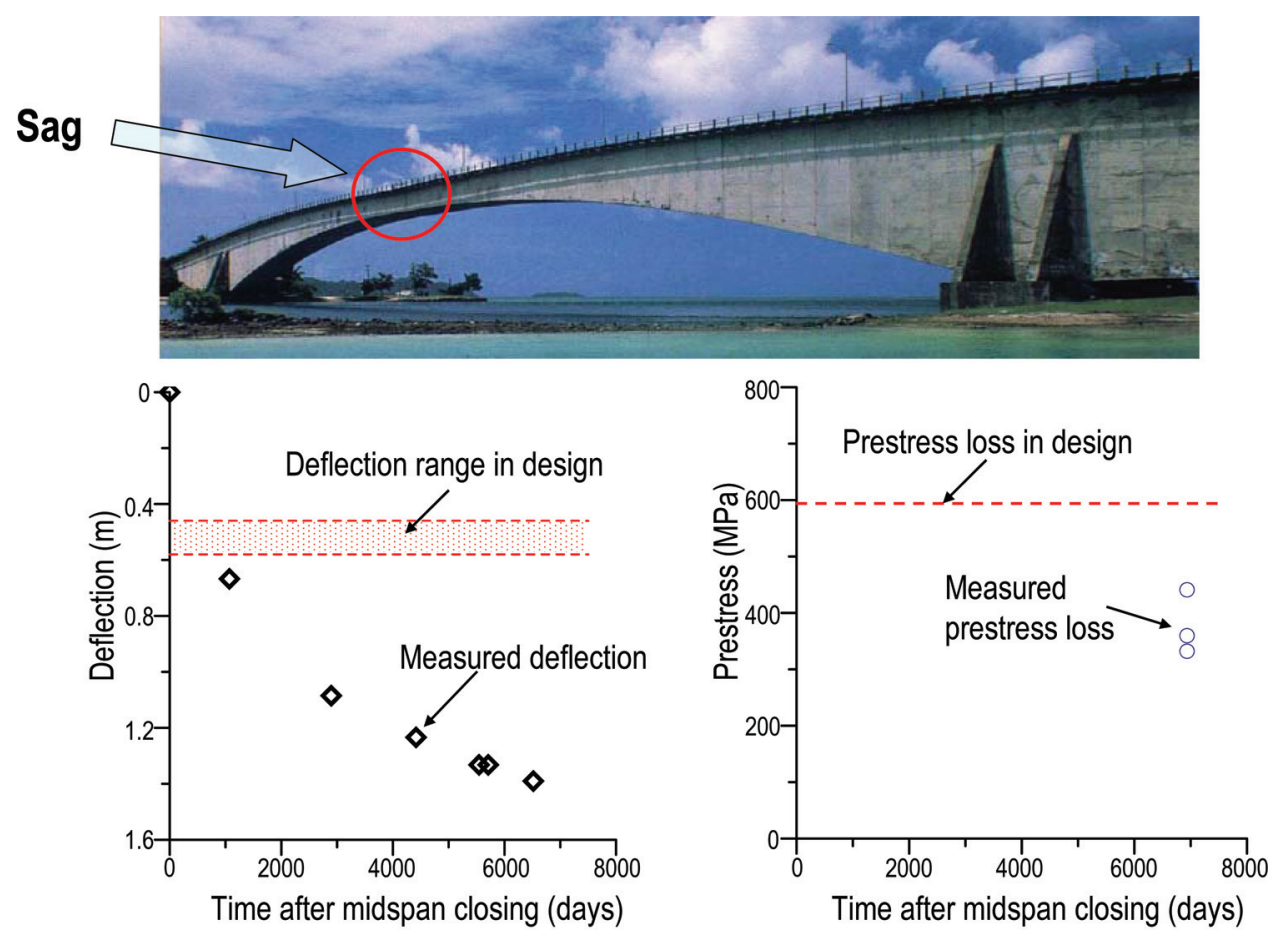

Fig. 1 -Excessive deflection recorded in KB Bridge in Palau. (Note: $1 \mathrm{~m}=3.28 \mathrm{ft} ; 1 \mathrm{MPa}$ = 145 psi.) 


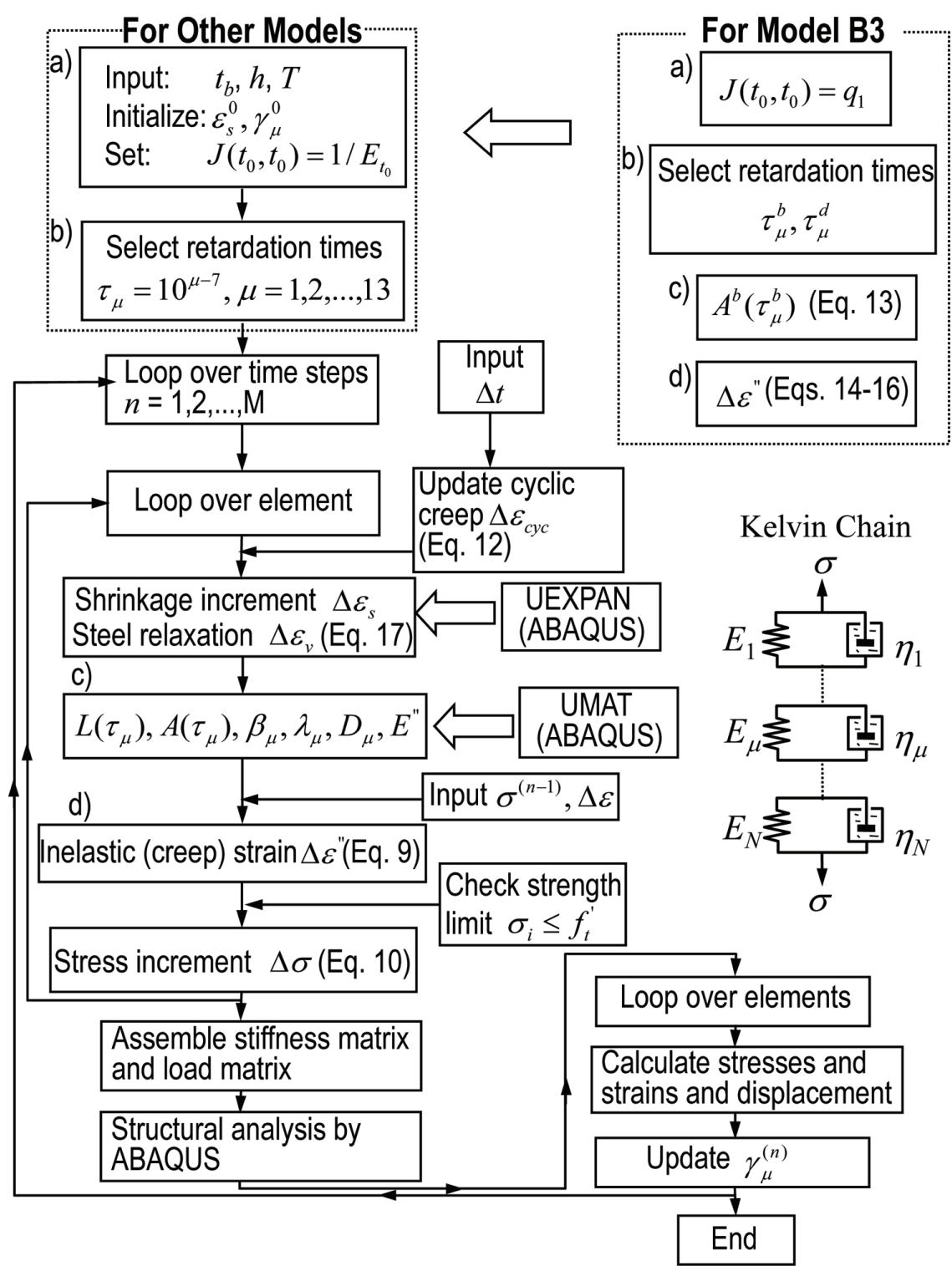

Fig. 2-Kelvin chain model and flowchart of algorithm of finite element creep analysis based on rate-type creep model.

In real design of large creep-sensitive structures, the integral-type creep law arising from the principle of superposition must be converted to an equivalent rate-type creep law with internal variables whose current values account for the previous history of viscoelastic strain. There are basically two reasons for choosing the rate-type approach:

1. One is computational: The strain history need not be stored and no sums over all the previous time steps need to be computed to approximate the history integrals. Thus, the ratetype approach makes creep computations far more efficient. For the design of very large structures, the rate-type form of creep law is almost inevitable. It also makes it easier to simulate the effects of numerous changes in the structural system, as in segmental construction with sequential prestressing of many segments or in super-tall building erection.

2. Another is the necessity to capture the phenomena causing deviations from the principle of superposition in time. ${ }^{19-21}$ These phenomena include the cracking and other damage of concrete, variations of humidity and temperature with the corresponding changes in the rate of aging (or hydration), bond slip, and cyclic creep. Upon inclusion of the nonlinear phenomena, the rate-type stress-strain relation ceases to obey the principle of superposition. A further highly nonlinear phenomenon is the stress relaxation of steel tendons, which is not viscoelastic. The evolution of steel relaxation may be significantly influenced by the strain variation in concrete and thus needs to be calculated as part of structural creep analysis to take into account the time variation of prestress loss due to the combined effects of concrete creep, shrinkage, and steel relaxation (note that the usual assumption of either a time-constant prestress loss or timevariable steel relaxation estimated in advance is generally insufficient for creep-sensitive structures).

The key property enabling the rate-type analysis is the fact that any realistic integral-type stress-strain relation of aging viscoelasticity can be approximated with any desired accuracy by a rate-type creep law visualized by the Kelvin chain model. This model consists of a series of Kelvin units $\mu=$ $1,2,3, \cdots, N$ (Fig. 2), each of which involves a spring of stiffness $E_{\mu}(t)$ coupled in parallel with a dashpot of viscosity $\eta_{\mu}(t)=E_{\mu}(t) \tau_{\mu}$, where $\tau_{\mu}$ are the suitably chosen retardation times. In step-by-step analysis, one takes advantage of the 
fact that, for a sufficiently short time step, $E_{\mu}$ and $\eta_{\mu}$ can be considered as approximately constant, although $E_{\mu}$ and $\eta_{\mu}$ generally change from one time step to the next.

The plot of compliances $A\left(\tau_{\mu}\right)=E_{\mu}{ }^{-1}$ versus $\log \tau_{\mu}$ is the discrete retardation spectrum. Because of aging, the spectrum is different for each subsequent time step. The discrete retardation times are best chosen to be spaced by decades in the logarithmic time scale-that is, $\tau_{\mu+1}=10 \tau_{\mu}$. For a sparser spacing of $\tau_{\mu}$, the representation of the compliance function by the discrete spectrum becomes bumpy and inaccurate, while a denser spacing gives no significant gain in accuracy.

When the rate-type creep law is used, the structural creep problem can be reduced to a system of first-order ordinary differential equations in time with age-dependent coefficients. Similar to the system of integral equations, however, this approach is a waste of effort. It is more efficient to convert the incremental stress-strain relation for each time step $\Delta t$ to a quasi-elastic incremental stress-strain relation. Thus, the structural creep problem gets reduced to a sequence of elasticity problems with initial strains ${ }^{19,20,22,23}$ (refer also to Section 29.3.5 in Jirásek and Bažant ${ }^{24}$ ).

\section{CONTINUOUS RETARDATION SPECTRA FOR SUBSEQUENT TIME STEPS}

A continuous retardation spectrum, which corresponds to the limit of an infinite Kelvin chain with infinitely many retardation times $\tau_{\mu}$ of infinitely close spacing, can be identified from the compliance data more conveniently than a discrete spectrum. It represents a smoothed-out plot of Kelvin unit compliances $E_{\mu}{ }^{-1}(t)$ versus $\log \tau_{\mu}$. Its advantage is that it is unique and can be identified from the given compliance function analytically by Laplace transform inversion (which is justified by the fact that, within a sufficiently short time step $\Delta t$, the aging of the material can be neglected). Widder's approximate inversion formula ${ }^{25}$ is effective for this purpose and gives ${ }^{25-28}$

$$
L\left(\tau_{\mu}\right)=-\frac{\lim _{k \rightarrow \infty}\left(-k \tau_{\mu}\right)^{k} C^{(k)}\left(k \tau_{\mu}\right)}{(k-1) !}
$$

where $C^{(k)}$ is the $k$-th order derivative on time $t$ of the creep part $C\left(t, t_{n-1 / 2}\right)$ of the compliance function $J\left(t, t_{n-1 / 2}\right) ; C\left(t, t^{\prime}\right)$ $=J\left(t, t^{\prime}\right)-1 / E_{0}$; and $E_{0}$ is the instantaneous (or short-time) elastic modulus. Note that, generally, $L\left(\tau_{\mu}\right)$ is different for each integration point of each finite element in each time step. The effects of thickness $t_{b}$, current local humidity $h$, current local temperature $T$, and so on are introduced into the spectrum through the compliance curve $J\left(t, t^{\prime}\right)$, in which $t^{\prime}$ is constant and represents the age of concrete in the middle of the current time step.

In practice, the limit in Eq. (1) need not be calculated and it suffices to use $k=3$. A discrete approximation of the continuous spectrum gives the discrete spectrum

$$
A\left(\tau_{\mu}\right)=\frac{1}{E\left(\tau_{\mu}\right)}=L\left(\tau_{\mu}\right) \ln 10 \Delta\left(\log \tau_{\mu}\right)=L\left(\tau_{\mu}\right) \ln 10
$$

which corresponds to a finite (or discrete) Kelvin chain and is required for numerical computations.

Note that, in the original rate-type creep analysis, ${ }^{29}$ the discrete spectrum $A\left(\tau_{\mu}\right)$ was calculated by least-square fitting of the compliance function $J\left(t, t^{\prime}\right)$, but this approach was found to give non-unique results for $A\left(\tau_{\mu}\right)$ and to be oversensitive to small changes in compliance. The continuous spectrum route is not only much simpler but also avoids this non-uniqueness and over-sensitivity. ${ }^{27}$

\section{NUMERICAL PROCEDURE USING EXPONENTIAL ALGORITHM FOR INCREASING TIME STEPS}

Every compliance function $J\left(t, t^{\prime}\right)$ can be represented with any desired accuracy by the Kelvin chain rheologic model, which converts the constitutive law for creep from a matrix of the Volterra integral equation to a system of ordinary firstorder linear differential equations for the rates of Kelvin unit strains $\varepsilon_{\mu}$. These are partial strains that represent what is known in thermodynamics as the internal variables (the Maxwell chain model can also be used but is less convenient because it requires converting $J\left(t, t^{\prime}\right)$ to the relaxation function $\left.R\left(t, t^{\prime}\right)\right)$. The equations for the $\varepsilon_{\mu}($ a $6 \times 1$ column matrix) read

$$
\begin{gathered}
D D_{\mu}(t)\left(\dot{\gamma}_{\mu}(t)+\frac{\gamma_{\mu}(t)}{\tau_{\mu}}\right)=\dot{\sigma}(t) \\
\gamma_{\mu}(t)=\tau_{\mu} \dot{\boldsymbol{\varepsilon}}_{\mu}(t)
\end{gathered}
$$

in which $\boldsymbol{\sigma}$ is the $6 \times 1$ column matrix of stress; $\boldsymbol{\varepsilon}_{\mu}$ is the partial strains $=$ strains of the individual Kelvin units $(6 \times$ 1 column matrixes); $D_{\mu}$ is the elastic moduli of Kelvin units (scalars); and $\boldsymbol{D}$ is the constant $6 \times 6$ elastic stiffness matrix for isotropic material with a unit value of Young's modulus, introduced under the simplifying assumption of a constant creep Poisson ratio, $v \approx 0.18$; and, with the notation $v^{*}=$ $(1-2 v) /(2(1-v))$.

$$
\boldsymbol{D}=\frac{1-v}{(1+v)(1-2 v)}\left(\begin{array}{cccccc}
1 & v /(1-v) & v /(1-v) & 0 & 0 & 0 \\
& 1 & v /(1-v) & 0 & 0 & 0 \\
& & 1 & 0 & 0 & 0 \\
& & & v^{*} & 0 & 0 \\
& & & & v^{*} & 0 \\
& & & & & v^{*}
\end{array}\right)(5)
$$

The usual algorithms for numerical integration of firstorder ordinary differential equations, such as the central or backward difference methods or the Runge-Kutta method, fail by numerical instability. The reason is that these methods are stable only if $\Delta t<<\tau_{1}$ while, to reach long times, the time steps $\Delta t$ need to be increased to values larger (in fact, many orders of magnitude larger) than the shortest retardation time $\tau_{\mu}=\tau_{1}$. An unconditionally stable algorithm, called the exponential algorithm, was devised to overcome this problem. ${ }^{20,23,29,30}$ In this algorithm, one calculates (for each integration point of each finite element, in each time step)

$$
\beta_{\mu}=e^{-\Delta t / \tau_{\mu}}, \quad \lambda_{\mu}=\tau_{\mu}\left(1-\beta_{\mu}\right) / \Delta t
$$




$$
\begin{gathered}
D_{\mu}=\frac{1}{A\left(\tau_{\mu}\right)\left(1-\lambda_{\mu}\right)} \\
\frac{1}{E^{\prime \prime}\left(t_{n-1 / 2}\right)}=\frac{1}{E_{0}}+\sum_{\mu=1}^{N} D_{\mu}^{-1}
\end{gathered}
$$

where $E^{\prime \prime}$ is the incremental modulus. The $6 \times 1$ column matrix of the inelastic strain increments, also called the eigenstrains, is obtained as

$$
\Delta \boldsymbol{\varepsilon}^{\prime \prime}=\sum_{\mu=1}^{N}\left(1-\beta_{\mu}\right) \boldsymbol{\gamma}_{\mu}^{(n-1)}
$$

The matrix of eigenstrains must now be augmented by the shrinkage (and thermal) strain increments in the current time interval, as well as the inelastic strain increments due to smeared cracking or other damage, and eventually also the cyclic creep (unless its simplified analysis is undertaken separately). Note that the last three terms in matrix $\Delta \varepsilon^{\prime \prime}$ represent the shear creep, which is normally neglected when the integral-type approach is used, although it is important for the shear lag in box girders. The 1-D stiffness in Eq. (8) is then used to construct the 3-D isotropic quasi-elastic matrix stress-strain relation with eigenstrains ${ }^{20,24}$

$$
\Delta \boldsymbol{\sigma}=E^{\prime \prime}\left(t_{n-1 / 2}\right) \boldsymbol{D}\left(\Delta \boldsymbol{\varepsilon}-\Delta \boldsymbol{\varepsilon}^{\prime \prime}\right)
$$

where $\Delta$ denotes the increments per time step, and matrixes $\boldsymbol{D}$ and $\Delta \varepsilon$ are generally non-isotropic. This stress-strain relation, which is different for each integration point of each finite element in each time step, is then used in an elastic structural analysis program. Thus, the structural creep problem gets reduced to a sequence of incremental elasticity problems, ${ }^{19,20,22-24}$ each of which can easily be solved by various commercial elastic finite element programs, such as ABAQUS. After solving the stress increment matrixes at all the integration points, the column matrix of the increments of internal variables of Kelvin chain units is then updated at each integration point as follows

$$
\gamma_{\mu}^{(n)}=\lambda_{\mu} \Delta \sigma D_{\mu}^{-1}+\beta_{\mu} \gamma_{\mu}^{(n-1)}
$$

Note that the history-that is, the values of $\boldsymbol{\gamma}_{\mu}^{(n)}, \boldsymbol{\varepsilon}_{\mu}$, and $\boldsymbol{\sigma}$ for the previous steps $1,2, \cdots, n-1$-need not be stored. The history is fully characterized by the current values of $\gamma_{\mu}^{(n)}$.

The exponential algorithm automatically captures the fact that every Kelvin unit whose retardation time $\tau_{\mu}$ is much shorter than $\Delta t$ behaves essentially as an elastic spring, as if the parallel dashpot did not exist. This property means that the compliances of the Kelvin units for which $\tau_{\mu}<\Delta t_{1}$ (the shortest time step) could be summed and all these units replaced by a single spring. This would reduce the amount of computations. For programming, though, it is simpler to keep all the Kelvin units, even those with remotely small $\tau_{\mu}$. It is important that the entire short-time tail of the spectrum be covered by $\tau_{\mu}$, especially when short time steps are used. ${ }^{7}$ Vice versa, the exponential algorithm also automatically captures the fact that the Kelvin units whose retardation times are an order of magnitude longer than the current time step behave essentially as rigid links.

A change of structural system, or an imposition of new constraints in a certain time step, is modeled by activating some previously deactivated finite elements (which is a standard feature in ABAQUS). This is, for example, necessary to simulate the sequential erection of segmental box girders (or of super-tall buildings). It also makes it possible to easily take into account the differences in the ages of various segments; the sequential prestressing at various times; the step-wise load increase in the individual segments during construction; the application of temporary construction loads (for example, the traveler truss weight); and the introduction of a new constraint, such as the joining of two opposite cantilevers after the segmental construction is completed.

In addition to construction sequence, ABAQUS can also automatically take into account the joining of two structural parts, as well as the jacking of a prestress tendon at the right time, in the form of a specified initial strain (or eigenstrain) in the tendons. The relaxation of steel tendons is introduced through the increments of inelastic strain in bar elements representing the tendons.

Compared to the integral-type approach, the rate-type approach has another big advantage. The incremental elastic stress-strain relation in each time step can further be modified according to cracking or other damage, cyclic creep, current humidity, current temperature, and current degree of hydration in the same way as it is done for inelastic timeindependent analysis. Note that this is not possible for the integral-type creep law because the cracking, humidity, and temperature, unlike concrete creep, do not have a memory and thus cannot be introduced into the history integrals. Furthermore, in contrast to the system of Volterra integral equations for statically indeterminate quantities, one can easily introduce the viscoplastic strain increments equivalent to the stress relaxation in steel tendons and thus solve the stress relaxation in prestressing steel as part of structural creep analysis (the result can be quite different from the standard estimates of prestress loss due to stress relaxation, as revealed by the analysis of the KB Bridge in Palau).

The derivation of the exponential algorithm for the ratetype form of aging viscoelasticity was originally given in Bažant ${ }^{30}$ and was presented in full detail in Bažant, ${ }^{19}$ RILEM Committee TC-69, ${ }^{20}$ and Bažant ${ }^{23}$ and in Section 29.3.5 of Jirásek and Bažant ${ }^{24}$ for a general compliance function. In Bažant and Prasannan, ${ }^{31,32}$ the derivation of a simpler special form was given for the special compliance function of the solidification theory and for Model B3. ${ }^{33,34}$ Calculation of the continuous retardation spectrum and its discretization were presented in Bažant and Xi. ${ }^{27}$

\section{GENERALIZATION FOR CYCLIC CREEP}

The cyclic creep (or fatigue deformations) caused by repeated traffic loads is not a major effect, but sometimes it can increase the deflections by approximately 2 to $5 \% .^{7} \mathrm{In}$ the case of Palau, ${ }^{7}$ it was calculated separately because it was negligible compared to the total deflection. However, for smaller-than-record spans or heavily loaded bridges with many lanes, especially those carrying cars and rail, the cyclic 
creep can be stronger and is better calculated as part of the general algorithm. According to Bažant and Kim, ${ }^{35}$ the additional inelastic strain due to the cyclic creep increment during time step $\Delta t$ may in general be roughly estimated as

$$
\Delta \varepsilon_{c y c}=g\left(f_{c y c}, \Delta \sigma, \sigma_{\max }\right) \Delta t
$$

where $g$ is an empirical function; $f_{c y c}$ is the frequency of normal stress cycles; $\sigma_{\max }$ is the maximum magnitude of normal stress; and $\Delta \sigma=\sigma_{\max }-\sigma_{\min }$ is the stress amplitude. For accurate analysis, the strains $\Delta \varepsilon_{c y c}$ should be calculated for each integration point of each finite element at each time step and added to the creep strain increments. But often the cyclic creep is very small and then a separate, simpler calculation is possible, as shown in Bažant et al. ${ }^{8}$ Calibration of Eq. (12) by test data of Gaede ${ }^{36}$ and others is the subject of a separate paper in preparation. Note that an alternative formula of Bažant and Kim ${ }^{35}$ and Bažant and Panula, ${ }^{37}$ which gives the cyclic creep as an acceleration of the static creep, appears to greatly underestimate the cyclic creep for multidecade loading.

\section{NUMERICAL IMPLEMENTATION AND ALGORITHM}

All the creep and shrinkage models predict the average (or effective) properties of creep and shrinkage over the thickness of a slab of the cross section directly from the environmental humidity, taking into account the slab thickness. This simplification is quite poor for cross sections subject to pure bending, partly because the creep prediction model has been calibrated by the tests under axial load. However, in flanged cross sections such as those of box girders, the distribution of longitudinal normal stress across the wall is nearly uniform - that is, the bending component within the wall alone is relatively small and the force resultant is nearly centric within the wall thickness. In that case, the aforementioned simplification works much better. It suffices to use only one finite element through the slab thickness, except in the top slab because that slab is subjected to transverse bending from roadway loads.

A computer program based on the algorithm described in the following was written and applied to the KB Bridge in Palau. ${ }^{3,6,7}$ This program (which can be freely downloaded from www.civil.northwestern.edu/people/Bažant/PDFs/Papers) can be adapted to other segmental bridges, as well as other types of concrete structures. On a state-of-the-art personal computer (PC) (for example, a quad-core, 4 GB memory), the entire 3-D finite element creep analysis of the KB Bridge ran for approximately 50 minutes. The flowchart of the algorithm used in this program is shown in Fig. 2.

Note that the number $N$ of internal variables could actually be reduced to approximately five, but then the first $L\left(\tau_{\mu}\right)$ $(\mu=1)$ would have to be computed as the integrated area under the spectrum up to $-\infty$ in the log-time scale (the reason is that Kelvin units with $\tau_{\mu}<<\Delta t$ behave as springs, and the compliances of springs coupled in series can be combined into one compliance). Using $N=22$ for Model B3 and $N=$ 13 for other models increases the demand on computer time and storage but is simpler to program, which is important for the user. The spectral values $L\left(\tau_{\mu}\right)$ for $\tau_{\mu} \gg t$ (the current time) are ignored because the corresponding Kelvin units behave as perfectly rigid.

\section{EXPONENTIAL ALGORITHM SIMPLIFICATIONS AND REFINEMENTS FOR MODEL B3}

The foregoing algorithm can also be used for Model B3, provided that the total compliance $J\left(t, t^{\prime}\right)$ is computed for each integration point. ${ }^{33,34}$ For basic creep, however, a simpler exponential algorithm exists, ${ }^{31,32}$ which needs only the compliance rate $\dot{J}\left(t, t^{\prime}\right)$. The compliance rate is directly specified by Model B3 and is applied only to the non-aging viscoelasticity of the non-aging constituent of growing volume $v(t)$. The modified steps of the algorithm, which are also shown in Fig. 2, involve the following equations

$$
\begin{gathered}
A^{b}\left(\tau_{\mu}^{b}\right)=\left(\sqrt{1 / t_{n-1 / 2}}+q_{3} / q_{2}\right) A\left(\tau_{\mu}^{b}\right) \\
\Delta \boldsymbol{\varepsilon}^{\prime \prime}=\Delta \boldsymbol{\varepsilon}_{1}^{\prime \prime}+\Delta \boldsymbol{\varepsilon}_{2}^{\prime \prime} \\
\Delta \boldsymbol{\varepsilon}_{1}^{\prime \prime}=\sum_{\mu=1}^{N^{b}}\left(\sqrt{1 / t_{n-1 / 2}}+q_{3} / q_{2}\right) \times\left(1-\beta_{\mu}\right) \boldsymbol{\gamma}_{\mu}^{(n-1)} \\
+\sum_{\mu=1}^{N^{d}}\left(1-\beta_{\mu}\right) \boldsymbol{\gamma}_{\mu}^{(n-1)} \\
\Delta \boldsymbol{\varepsilon}_{2}^{\prime \prime}=q_{4} \boldsymbol{\sigma}^{(n-1)} \Delta t / t_{n-1 / 2}
\end{gathered}
$$

where $A^{b}\left(\tau_{\mu}^{b}\right)$ is the discretized spectrum for the non-aging constituent in Model B3; $\boldsymbol{\varepsilon}_{1}{ }_{1}$ is the $6 \times 1$ column matrix (vector) of the inelastic strain increments in the current volume fraction of solids; and $\boldsymbol{\varepsilon}_{2}{ }_{2}$ is the $6 \times 1$ column matrix of inelastic strain increment of viscous flow.

More realistic is an analysis in which the relative humidity $h_{p}$ in the capillary pores of concrete at various points and times is computed from the nonlinear diffusion equation for concrete drying, ${ }^{38,39}$ for which a 1-D version for transverse moisture transport is generally sufficient. This approach further has the advantage that the creep and shrinkage law for a material point is simpler and more accurate than it is for the cross-section average.

Model B3 includes an alternative that allows such pointwise calculation of creep and shrinkage. In this case, the thickness of the slab needs to be subdivided into at least six finite elements, which increases the number of all finite elements in the structure approximately six times. The integration of the diffusion equation for drying (and wetting) of concrete $^{38}$ is done numerically, simultaneously with creep structural analysis. This more refined approach is a straightforward generalization of the present approach and will not be discussed further.

\section{PRESTRESSING STEEL RELAXATION AT VARIABLE STRAIN}

So far, the practice has been to calculate the stress relaxation in prestressing tendons from simple formulas that give 
relaxation at constant strain $\varepsilon$. As exemplified by the KB Bridge in Palau, however, the strain variation in steel bonded to concrete need not be negligible when dealing with creepsensitive structures. Also, the exposure of pavement to sun can cause significant heating of tendons embedded in the top slab. ${ }^{7}$ Therefore, one needs a general uniaxial viscoplastic constitutive law for prestressing steel (Chapter 27 of Reference 24). Plenty of test data on prestressing steel relaxation exist for constant strain and constant room temperature. ${ }^{40}$ The most extensive are given in Magura et al. ${ }^{41}$ The data for variable strain and variable temperature are much more limited but those that exist ${ }^{42,43}$ suffice for calibration. It is clear that the equation governing the relaxation of prestressing steel must have the form of a viscoplastic constitutive law, which gives the inelastic strain increment in steel as follows

$$
\Delta \varepsilon_{v}=f\left(\varepsilon, \sigma_{p}\right) A_{T} \Delta t+\alpha \Delta T
$$

where $\sigma_{p}$ is the current stress in steel tendons; $\varepsilon$ is the current strain in tendons, which must be the same as in the adjacent concrete; $\Delta T$ is the increment of temperature; $\alpha$ is the thermal expansion coefficient of steel; and $A_{T}$ is the temperature factor, which equals 1 at room temperature. A realistic expression for function $f\left(\varepsilon, \sigma_{p}\right)$ which, for constant $\varepsilon$, constant $T$, and high $\sigma_{p}$, reduces to the CEB-fib formula and also incorporates a threshold co-opted from American practice, has been derived and calibrated by test data in Bažant and $\mathrm{Yu}^{40}$; refer to the Appendix.

\section{CHECK OF PROGRAMMING WITH SIMPLE NUMERICAL EXAMPLE}

The user can check the correctness of programming of the exponential algorithm by the following example, which uses the compliance function $J\left(t, t^{\prime}\right)=\left[1+\phi\left(t, t^{\prime}\right)\right] / E\left(t^{\prime}\right)$ in which, according to ACI Committee $209^{44,45}$

$$
\phi\left(t, t^{\prime}\right)=2.35 \gamma_{c} \frac{\left(t-t^{\prime}\right)^{0.6}}{10+\left(t-t^{\prime}\right)^{0.6}}
$$

$\gamma_{c}$ is the empirical factor accounting for age $t^{\prime}$ at loading, humidity, slab thickness, concrete slump, and contents of fine aggregates and air. The cyclic creep cannot be combined with Eq. (18).

The ACI 209 function (Eq. (18)) is used not because it would be realistic (it is not) but because it is the simplest to check the correctness of programming. For practical use in design, this function should be replaced by a realistic one.

In ABAQUS, the exponential algorithm is used in the user material subroutine (UMAT):

1. At $t=t_{0}$, initialize the internal variables: $\boldsymbol{\gamma}_{\mu}^{(0)}=0, J\left(t_{0}, t_{0}\right)$ $=1 / E\left(t_{0}\right)$, where $t_{0}$ is the time when the first load is applied. Select $\tau_{\mu}=10^{-7+\mu}(\mu=1,2, \cdots, 13)$;

2. Use Widder's formula ${ }^{25-27}$ to calculate the continuous spectrum; also refer to Eq. (1)

$$
\begin{gathered}
d^{3} \phi / d^{3} \xi^{3}=\Psi(\xi)=2.35 \gamma_{c} \\
\times\left[0.336 \xi^{-2.4}\left(10+\xi^{0.6}\right)^{-1}+0.528 \xi^{-1.8}\left(10+\xi^{0.6}\right)^{-2}\right. \\
\left.+0.432 \xi^{-1.2}\left(10+\xi^{0.6}\right)^{-3}-1.296 \xi^{-0.6}\left(10+\xi^{0.6}\right)^{-4}\right]
\end{gathered}
$$

where $\xi=t-t^{\prime}, L\left(\tau_{\mu}\right)=2.35 \gamma_{c}\left(3 \tau_{\mu}\right)^{3} \Psi\left(3 \tau_{\mu}\right) / 2 ; \gamma_{c}$ is calculated using $t_{n-1 / 2}$;

3. Discretized spectrum; also refer to Eq. (2): $A\left(\tau_{\mu}\right)=L\left(\tau_{\mu}\right)$ $\ln 10 / E\left(t_{n-1 / 2}\right)$;

4. Calculate $\beta_{\mu}, \lambda_{\mu}$, and $D_{\mu}$; refer to Eq. (6) and (7);

5. Calculate the effective modulus $E^{\prime \prime-1}\left(t_{n-1 / 2}\right)$; refer to Eq. (8);

6. Obtain the creep strain increment matrix $\Delta \boldsymbol{\varepsilon}^{\prime \prime}$; refer to Eq. (9);

7. The stress-strain relation for this integration point is

$$
\boldsymbol{\Delta} \boldsymbol{\sigma}=E^{\prime \prime}\left(t_{n-1 / 2}\right) \boldsymbol{D}\left(\boldsymbol{\Delta} \boldsymbol{\varepsilon}-\Delta \boldsymbol{\varepsilon}^{\prime \prime}\right) ; \text { refer to Eq. (10). }
$$

The loop repeats these calculations for all the integration points of all finite elements and supplies the stiffness and load matrixes of the incremental stress-strain relations for the assembly of the structural stiffness and load matrixes. Then, ABAQUS runs the incremental elastic finite element analysis; and

8. After retrieving the stress increments computed by ABAQUS, update for each finite element the internal variables $\gamma_{\mu}^{(n)}$; refer to Eq. (11). Then begin the next time step, unless the lifetime has been reached.

Using $\gamma_{c}=1.25\left(t^{\prime}\right)^{-0.118}$

$$
E_{t}=E_{28} \sqrt{t /(4+0.85 t)}
$$

(where $E_{28}=E$ at 28 days of age $\left.=30 \mathrm{GPa}[4350 \mathrm{ksi}]\right)$, and uniaxial loading by $\sigma=1 \mathrm{MPa}(145 \mathrm{psi})$ applied at $t_{0}=$ 7 days, one should get: $\varepsilon=4.92 \times 10^{-5}=$ for $t=8$ days, $\varepsilon=$ $9.68 \times 10^{-5}$ for $t=100$ days, $\varepsilon=0.00012$ for $t=1000$ days, and $\varepsilon=0.000129$ for $t=10,000$ days. The ACI formula gives almost the same results; refer to Fig. 3.

\section{COMPARISON WITH EXISTING COMMERCIAL DESIGN SOFTWARE PROGRAMS}

Commercial programs, whose basic form was developed around 1980, are generally used for the creep design of prestressed box girder bridges. They include SOFiSTiK, SCIA-Engineer, InfoCAD, and RSTAB/RFEM software (distributed by the Ingenieur-Software Dlubal $\mathrm{GmbH}$, Germany). ${ }^{46-49}$ The material creep and shrinkage model, typically the CEB Model, is embedded in these programs. In these programs, all the nonlinear, cracking, diffusion, cyclic creep, and drying effects are neglected. So are the environmental variations, heating of tendons, and relaxation affected by concrete strain. An example of such a commercial code is SOFiSTiK, which is the only program used herein. Therefore, the conclusions that follow are verified only for SOFiSTiK, although they probably apply to the aforementioned other similar software programs. For 1-D analysis, in which the box girder is represented by beam elements, 

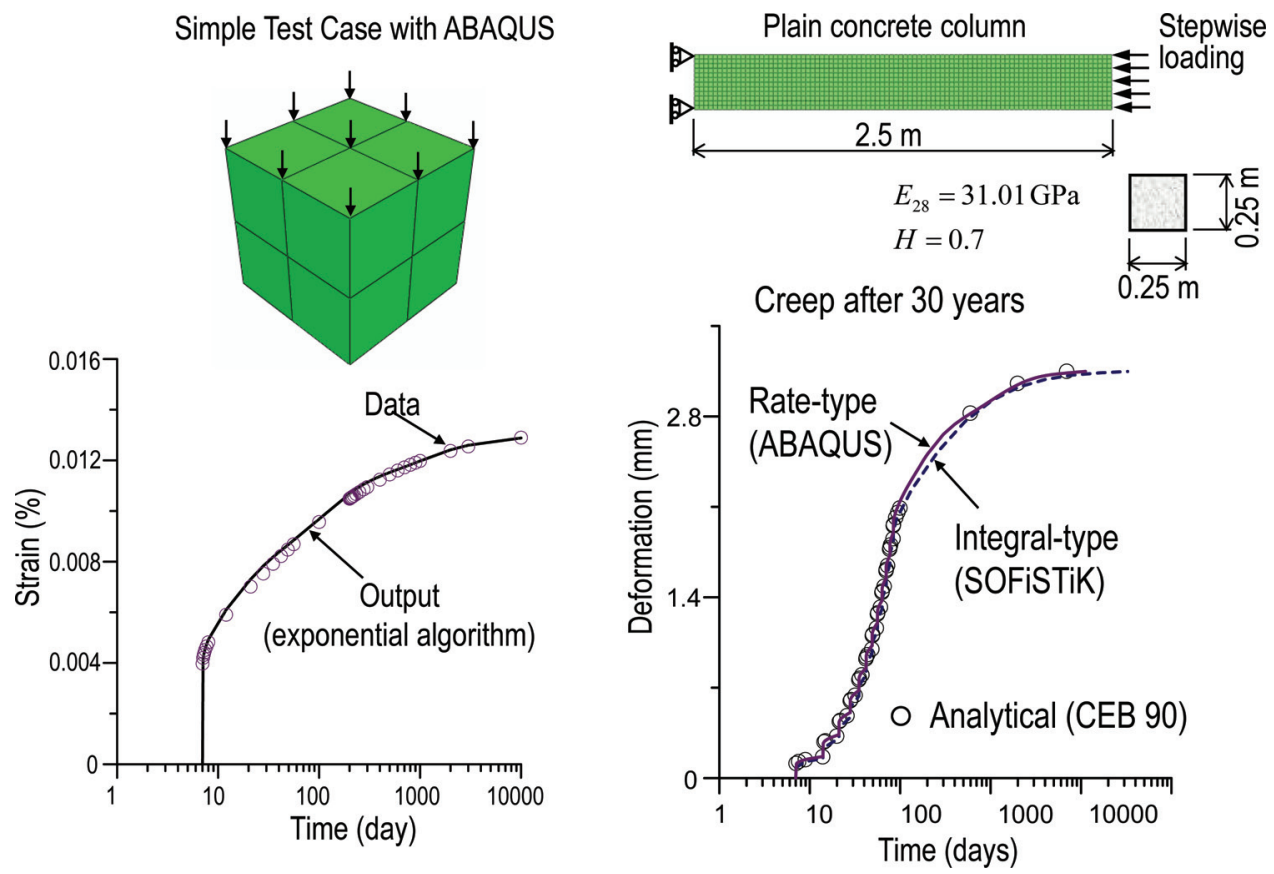

Fig. 3-Left: simulation results by ABAQUS compared with ACI formula; and right: results for elementary example of freestanding column, in which curves show comparison of creep analysis results obtained with present rate-type algorithm and integral-type algorithm run in commercial program SOFiSTiK. (Note: $1 \mathrm{~m}=3.28 \mathrm{ft} ; 1 \mathrm{GPa}=145 \mathrm{ksi} ; 1 \mathrm{~mm}=0.0394 \mathrm{in}$.)

the creep is modeled by linear aging viscoelasticity, which is implemented in the primitive form of an integral-type creep law (as introduced for nuclear reactor structures before 1970). The memory integrals are numerically integrated step by step from the complete stress history of each beam element, which increases the demands on computer time and storage. This fact, and the need to investigate many load cases and combinations, are probably the reasons why, despite the availability of two-dimensional (2-D) and 3-D finite elements, SOFiSTiK does not use the memory integrals in combination with these elements. Rather, in the case of 2-D or 3-D elements, SOFiSTiK uses a simple quasielastic algebraic analysis based on a one-step incremental elastic relation of the following uniaxial form

$\sigma(t)-\sigma\left(t_{1}\right)=E^{\prime \prime}\left(t, t_{1}\right)\left[\varepsilon(t)-\phi\left(t, t_{1}\right) \varepsilon\left(t_{1}\right)-\varepsilon_{s h}\left(t, t_{1}\right)\right]$

where $\sigma, \varepsilon$ is axial stress and strain; $t_{1}$ is the age of concrete at load application; $t$ is current age; $\varepsilon\left(t_{1}\right)$ is initial elastic strain at $t_{l} ; \phi\left(t, t_{1}\right)$ and $\varepsilon_{s h}$ are creep coefficient and shrinkage strain, respectively, as specified by the 1990 CEB Model Code; and $E^{\prime \prime}\left(t, t_{1}\right)$ is the incremental Young's modulus for the entire period from $t_{1}$ to $t$. According to the 1967 Trost method ${ }^{50} E^{\prime \prime}=E_{28} /(1+\rho \phi)$, where $\rho$ is Trost's so-called relaxation coefficient, typically taken as 0.8 .

But $\rho$ and $E_{28}$ do not take into account the creep aging. This effect can be captured by the age-adjusted effective modulus (AAEM) method, ${ }^{20,23,24,51}$ in which $E_{28}$ is replaced with $E(t)$ and $\rho$ with aging coefficient $\chi$, as shown in 1972 by Bažant. ${ }^{51}$ The AAEM has been endorsed since 1982 by
ACI Committee 209 and since 1990 by the CEB Model Code, yet no update has been made in SOFiSTiK (nor RSTAB/RFEM or InfoCAD).

By virtue of taking the aging into account, the errors of the AAEM for loads applied at a young age (which is a typical situation for box girder segments) are significantly smaller, compared to the exact linear viscoelastic solutions, than the errors of the Trost method. ${ }^{24,52}$ The AAEM often gives surprisingly good estimates of the linear aging viscoelastic solutions in simple beam structures. However, even if SOFiSTiK switched to AAEM, much larger errors due to the use of quasi-elastic analysis for multi-dimensional finite elements and of pure linear viscoelasticity for 1-D beam elements would still remain.

Although the major source of error in a program such as SOFiSTiK is the embedded CEB creep model, one must accept this model to isolate other errors through numerical examples. The first example is a freestanding plain concrete column under uniaxial compression. The relevant concrete properties are $f_{c 28}=30 \mathrm{MPa}$ (4350 psi) (which gives $E_{28}=$ $31,008 \mathrm{MPa}$ [4496.2 ksi] according to the CEB formula) and an environmental humidity $h=70 \%$. The first compressive stress $\sigma^{(1)}=1 \mathrm{MPa}(145 \mathrm{psi})$ is applied at $t_{0}=7$ days and subsequently additional compressive stresses $\sigma^{(i)}=1 \mathrm{MPa}$ (145 psi) $(i=2,3, \cdots, 12)$ are applied every 7 days. It is found that, in this example, the integral-type algorithm of SOFiSTiK predicts the creep deformations accurately enough. The deviations from the exact analytical solution and the present algorithm are barely distinguishable (Fig. 3).

The second example is the ill-fated KB Bridge in Palau. The information about this bridge can be found in investigation reports and recent studies. ${ }^{1-3,6,7,18,53}$ To explain the unexpected huge deflection, a comprehensive investigation of this 


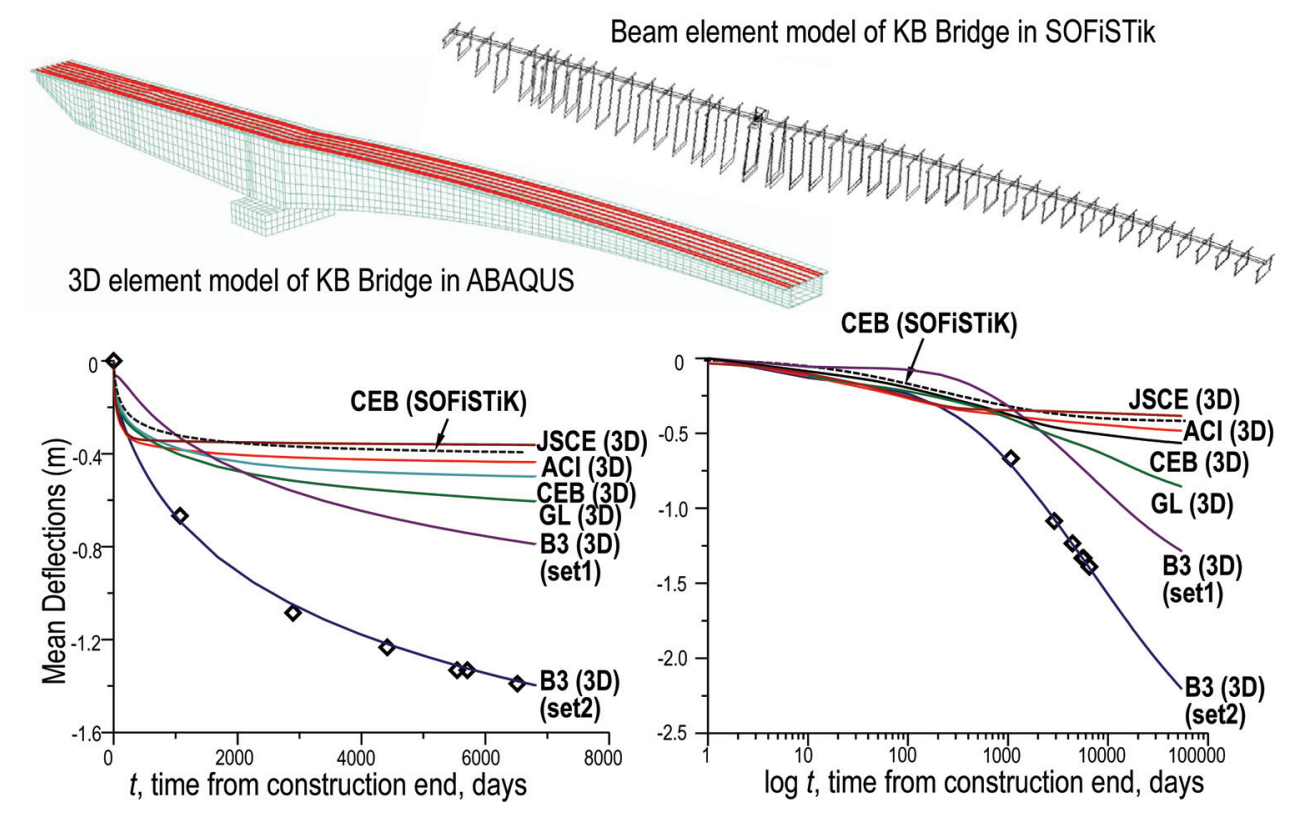

Fig. 4-Comparison of simulation results of $K B$ Bridge by rate-type 3-D analysis and SOFiSTik. (Note: $1 \mathrm{~m}=3.28 \mathrm{ft}$.)

bridge was carried out at Northwestern University ${ }^{3,6,7}$; refer also to Fig. 4. By applying the present rate-type algorithm to 3 -D analysis, the long-term deflections have been computed for different creep and shrinkage models, as plotted in Fig. 4 with respect to the end of construction. As seen in the figure, such analysis based on Model B3 can match the measured deflection very well, provided the creep parameters are calibrated by the long-term creep tests of Brooks ${ }^{11,12}$; refer to B3 (Set 2) in Fig. 4.

Unlike the rate-type analysis with ABAQUS, SOFiSTiK uses a simplified approach with 45 nodes and 44 beam elements corresponding to the segmental construction ${ }^{2,3,6,7}$; refer to Fig. 4. The prestressing system is modeled by 44 tendon groups consisting of six to 40 individual $32 \mathrm{~mm}$ (1.25 in.) diameter threaded alloy bars with $1030 \mathrm{MPa}$ (150 ksi) nominal tensile strength, which are assumed to be located in the center of the top slab. The jacking force for each tendon is $600 \mathrm{kN}$ (135 kips) with $5 \%$ of initial prestress loss. According to the design specifications, the 28-day concrete properties are $f_{c}^{\prime}=35.9 \mathrm{MPa}$ (5207 psi) and $E_{c}=28.3 \mathrm{GPa}(4105 \mathrm{ksi})$. The pier and foundation are substituted by an idealized vertical spring of $k_{z}=1.42 \times$ $10^{8} \mathrm{kN} / \mathrm{m}\left(9.73 \times 10^{6} \mathrm{kip} / \mathrm{ft}\right)$ and a rotational spring of $k_{m, y}$ $=1.42 \times 10^{9} \mathrm{kN}-\mathrm{m} / \mathrm{rad}\left(1.05 \times 10^{9} \mathrm{kip}-\mathrm{ft} / \mathrm{rad}\right)$. The CEB Model $1990^{54}$ is used not only for concrete creep but also for steel relaxation. The steel relaxation evolution is handled in SOFiSTiK either by a fixed 1000-hour relaxation factor or, as chosen in this example, by the stress-dependent quadratic function according to the CEB Model Code 1990, ${ }^{54}$ interpolated from three points: $2 \%$ at $0.60 f_{p k}, 4 \%$ at $0.70 f_{p k}$, and $6.67 \%$ at $0.80 f_{p k}$, where $f_{p k}$ is the characteristic tensile strength of the prestressing tendons. Although the actual calculations in SOFiSTiK are a black box, the specified quadratic CEB relaxation function in itself is not a good approximation for multi-decade relaxation. ${ }^{40}$ For the creep and shrinkage analysis, the age at start of drying is taken as $t_{0}=7$ days, which is also the assumed segmental erection cycle. The average environmental humidity is $h=0.70$. In each erection cycle, one segment, including its dead load, is added and prestressed at the end of the 7-day period.

The linear viscoelastic analysis of the KB Bridge in SOFiSTiK (modeled as beam) predicts substantially less deflection than the recorded measurements, which are represented by the diamonds in Fig. 4. Furthermore, when compared with the rate-type 3-D analysis, which uses the same CEB model, SOFiSTiK also substantially underpredicts the creep deflection. The integral-type algorithm used in this calculation gives a deflection of only approximately $79 \%$ of the value predicted by the CEB Model Code when applied in the ABAQUS 3-D analysis, which itself underestimates the observed creep deflections by a factor of approximately $1 / 3$; refer to Fig. 4.

Even if the viscoelastic analysis and finite element simulation were perfect, SOFiSTiK and similar design software programs cannot correctly simulate the nonlinear evolution of viscoplastic steel relaxation at variable strain, the variations of temperature and humidity, and the nonlinear effects of cracking and cyclic loading (although a correction for cracking can, of course, be made in a time step; this would be incorrect in combination with memory integrals for creep because the cracking has no delayed memory). The effects of wall thickness differences among the top slab, walls, and bottom slab on the drying creep and shrinkage can only be captured by more refined models using a rate-type creep law and 2-D or 3-D finite elements.

\section{SUMMARY AND CONCLUSIONS}

1. Although many ingredients of the present algorithm have been developed separately-some of them long ago $^{19,22,24,27,29-31,33,34,55}$ - this paper combines them into one comprehensive algorithm, gives the previously missing details needed for programming, and incorporates into the 
algorithm two innovations: 1) the method of continuous retardation spectrum, adapted for creep prediction models other than those based on the solidification theory (that is, other than Model B3) ${ }^{3}$; and 2) the dependence of prestressing steel relaxation on temperature and the variation of strain, based on the theory of viscoplasticity of metals.

2. While the previously developed ingredients of the formulation have been used mainly in research studies of nuclear containments, reactor vessels, and segmental box girders, herein they are amalgamated into one comprehensive algorithm intended for creep-sensitive design.

3 . The recent compilation of data on excessive deflections of numerous bridges ${ }^{8-10}$ and the detailed analysis of some of them ${ }^{3,6,7}$ reveal that the creep analysis based on a rate-type creep law, which can capture various nonlinear and drying effects, as well as a complex evolution of the loading and structural system, is a necessity for all large structures of high creep sensitivity if serviceability and lifetimes in excess of 20 to 40 years are to be ensured.

4. Evaluation of the existing commercial software programs reveals that they strongly underestimate the effects of multi-decade creep in large-span prestressed bridges (and probably in columns of tall buildings as well). Except for possible cases of deliberate overdesign and special deflection mitigating measures, a continued use of such outdated software would likely compromise the durability of structures. A major update of this software is requisite. For smaller-span structures dominated by live load, the use of this software is likely harmless but also superfluous - a much simpler analysis based on the effective (or sustained) modulus for creep would suffice.

\section{ACKNOWLEDGMENTS}

Financial support was provided by the U.S. Department of Transportation through Grant 20778 from the Infrastructure Technology Institute of Northwestern University and National Science Foundation Grants CMMI1129449 and CMMI-1153494. M. Jirásek of the Czech Technical University in Prague is thanked for stimulating critical comments.

\section{REFERENCES}

1. Pilz, M., "Untersuchungen zum Einsturz der KB Brücke in Palau," Beton- und Stahlbetonbau, V. 94, No. 5, May 1999, pp. 229-232.

2. McDonald, B.; Saraf, V.; and Ross, B., "A Spectacular Collapse: The Koro-Babeldaob (Palau) Balanced Cantilever Prestressed, Post-Tensioned Bridge," The Indian Concrete Journal, V. 77, No. 3, Mar. 2003, pp. 955-962.

3. Bažant, Z. P.; Yu, Q.; Li, G.-H.; Klein, G. J.; and Křístek, V., "Excessive Deflections of Record-Span Prestressed Box Girder: Lessons Learned from the Collapse of the Koror Babeldaob Bridge in Palau," Concrete International, V. 32, No. 6, June 2010, pp. 44-52.

4. Nawy, E. G., Prestressed Concrete: A Fundamental Approach, fifth edition, Pearson Prentice Hall, Upper Saddle River, NJ, 2006, 984 pp.

5. Nilson, A. H., Design of Prestressed Concrete, second edition, John Wiley \& Sons, Inc., New York, 1987, 608 pp.

6. Bažant, Z. P.; Yu, Q.; and Li, G.-H., "Excessive Long-Time Deflections of Prestressed Box Girders: I. Record-Span Bridge in Palau and Other Paradigms," Journal of Structural Engineering, ASCE, V. 138, No. 6, 2012, pp. 676-686.

7. Bažant, Z. P.; Yu, Q.; and Li, G.-H., "Excessive Long-Time Deflections of Prestressed Box Girders: II. Numerical Analysis and Lessons Learned," Journal of Structural Engineering, ASCE, V. 138, No. 6, 2012, pp. 687-696.

8. Bažant, Z. P.; Hubler, M.; and Yu, Q., "Excessive Creep Deflections: An Awakening," Concrete International, V. 33, No. 8, Aug. 2011, pp. 44-46.

9. Bažant, Z. P.; Yu, Q.; Hubler, M.; Kř́stek, V.; and Bittnar, Z., "Wake-Up Call for Creep, Myth about Size Effect and Black Holes in Safety: What to Improve in fib Model Code Draft," Concrete Engineering for Excellence and Efficiency Proceedings of the fib Symposium, Prague, Czech Republic, 2011, pp. 731-746.

10. Bažant, Z. P.; Hubler, M. H.; and Yu, Q., "Pervasiveness of Excessive Segmental Bridge Deflections: A Wake-Up Call for Creep," ACI Structural Journal, V. 108, No. 6, Nov.-Dec. 2011, pp. 766-774.
11. Brooks, J. J., "30-Year Creep and Shrinkage of Concrete," Magazine of Concrete Research, V. 57, No. 9, 2005, pp. 545-556.

12. Brooks, J. J., "Accuracy of Estimating Long-Term Strains in Concrete," Magazine of Concrete Research, V. 36, No. 128, 1984, pp. 131-145.

13. Troxell, G. E.; Raphael, J. E.; and Davis, R. W., "Long-Time Creep and Shrinkage Tests of Plain and Reinforced Concrete," Proceedings, ASTM, V. 58, 1958, pp. 1101-1120.

14. Benscoter, S. U., "A Theory of Torsion Bending for Multi-Cell Beams," Journal of Applied Mechanics, V. 21, No. 1, 1954, pp. 25-34.

15. Malcolm, D. J., and Redwood, R. G., "Shear Lag in Stiffened Box Girders," Journal of the Structural Division, ASCE, V. 96, No. ST7, July 1970, pp. 1403-1419.

16. Reissner, E., "Analysis of Shear Lag in Box Beams by the Principle of Minimum Potential Energy," Quarterly of Applied Mechanics, V. 4, No. 3 , 1946, pp. 268-278.

17. Parker, D., "Tropical Overload," New Civil Engineering, Dec. 1996, pp. $18-21$

18. Pilz, M., "The Collapse of the KB Bridge in 1996," dissertation, Imperial College London, London, UK, 1997.

19. Bažant, Z. P., "Mathematical Models for Creep and Shrinkage of Concrete," Creep and Shrinkage in Concrete Structures, Z. P. Bažant and F. H. Wittmann, eds., John Wiley \& Sons, Inc., London, UK, 1982, pp. 163-256.

20. RILEM Committee TC-69, "State of the Art in Mathematical Modeling of Creep and Shrinkage of Concrete," Mathematical Modeling of Creep and Shrinkage of Concrete, Z. P. Bažant, ed., John Wiley \& Sons, Inc., Chichester, UK, and New York, 1988, pp. 57-215.

21. Bažant, Z. P.; Li, G.-H.; and Yu, Q., "Prediction of Creep and Shrinkage and Their Effects in Concrete Structures: Critical Appraisal," Creep, Shrinkage and Durability Mechanics of Concrete and Concrete Structures (Proceedings of the 8th International Conference-CONCREEP-8, IseShima, Japan), T. Tanabe, K. Sakata, H. Mihashi, R. Sato, K. Maekawa, and H. Nakamura, eds., CRC Press/Balkema, Taylor \& Francis Group, Boca Raton, FL, and London, UK, 2008, pp. 1275-1289.

22. Bažant, Z. P., "Linear Creep Problems Solved by a Succession of Generalized Thermoelasticity Problems," Acta Technica CSAV, V. 12, No. 5, 1967, pp. 581-594

23. Bažant, Z. P., "Theory of Creep and Shrinkage in Concrete Structures: A Précis of Recent Developments," Mechanics Today, S. NematNasser, ed., V. 2, 1975, pp. 1-93.

24. Jirásek, M., and Bažant, Z. P., Inelastic Analysis of Structures, John Wiley \& Sons, Inc., London, UK, and New York, 2002, 722 pp.

25. Widder, D. V., The Laplace Transform, Princeton University Press, Princeton, NJ, 1941, 416 pp.

26. Widder, D. V., An Introduction to Transform Theory, Academic Press, New York, 1971, 253 pp.

27. Bažant, Z. P., and Xi, Y., "Continuous Retardation Spectrum for Solidification Theory of Concrete Creep," Journal of Engineering Mechanics, ASCE, V. 121, No. 2, 1995, pp. 281-288.

28. Tschoegl, N. W., The Phenomenological Theory of Linear Viscoelastic Behavior: An Introduction, Springer Verlag, Berlin, Germany, 1989, 769 pp.

29. Bažant, Z. P., and Wu, S. T., "Dirichlet Series Creep Function for Aging Concrete," Proceedings, Journal of the Engineering Mechanics Division, ASCE, V. 99, No. EM2, 1973, pp. 367-387.

30. Bažant, Z. P., "Numerically Stable Algorithm with Increasing Time Steps for Integral-Type Aging Creep," Proceedings, First International Conference on Structural Mechanics in Reactor Technology (SMiRT-1), T. A. Jaeger, ed., V. 4, Part H, West Berlin, Germany, 1971, pp. 119-126.

31. Bažant, Z. P., and Prasannan, S., "Solidification Theory for Concrete Creep: I. Formulation," Journal of Engineering Mechanics, ASCE, V. 115, No. 8, 1989, pp. 1691-1703.

32. Bažant, Z. P., and Prasannan, S., "Solidification Theory for Concrete Creep: II. Verification and Application," Journal of Engineering Mechanics, ASCE, V. 115, No. 8, 1989, pp. 1704-1725.

33. Bažant, Z. P., and Baweja, S., "Creep and Shrinkage Prediction Model for Analysis and Design of Concrete Structures: Model B3," Materials and Structures, V. 28, 1995, pp. 357-367.

34. Bažant, Z. P., and Baweja, S., "Creep and Shrinkage Prediction Model for Analysis and Design of Concrete Structures: Model B3," Adam Neville Symposium: Creep and Shrinkage-Structural Design Effects, SP-194, A. Al-Manaseer, ed., American Concrete Institute, Farmington Hills, MI, 2000, pp. 1-83.

35. Bažant, Z. P., and Kim, J.-K., "Improved Prediction Model for TimeDependent Deformations of Concrete: Part 5-Cyclic Load and Cyclic Humidity," Materials and Structures, V. 25, No. 147, 1992, pp. 163-169.

36. Gaede, K., "Versuche über die Festigkeit und die Ferformung von Beton bei Druck-Schwellbeanspruchung und über den Einfluss der Grösse 
der Proben auf die Würfeldruchfestigkeit von Beton," Deutscher Ausschuss Fr Stahlbeton, Heft 144, 1962. (in German)

37. Bažant, Z. P., and Panula, L., "Practical Prediction of Time-Dependent Deformations of Concrete: Part 6-Cyclic Creep, Nonlinearity and Statistical Scatter," Materials and Structures, V. 12, 1979, pp. 175-183.

38. Bažant, Z. P., and Najjar, L. J., "Nonlinear Water Diffusion in Nonsaturated Concrete," Materials and Structures, V. 5, 1972, pp. 3-20.

39. Bažant, Z. P.; Křístek, V.; and Vítek, J. L., "Drying and Cracking Effects in Box-Girder Bridge Segment," Journal of Structural Engineering, ASCE, V. 118, No. 1, 1992, pp. 305-321.

40. Bažant, Z. P., and Yu, Q., "Constitutive Equation for Prestress Relaxation at Varying Strain and Temperature," Structural Engineering Report No. 10-10/778c, Northwestern University, Evanston, IL, 2010.

41. Magura, D. D.; Sozen, M. A.; and Siess, C. P., "A Study of Stress Relaxation in Prestressing Reinforcement," PCI Journal, V. 9, No. 2, Apr. 1964, pp. 13-57.

42. Buckler, J. D., and Scribner, C. F., "Relaxation Characteristics of Prestressing Strand," Engineering Studies, Report No. UILU-ENG-85-2011, University of Illinois, Urbana, IL, 1985, 84 pp.

43. Rostásy, F. S., and Thienel, K.-C., "On Prediction of Relaxation of Colddrawn Prestressing Wire under Constant and Variable Elevated Temperature," Nuclear Engineering and Design, V. 130, 1991, pp. 221-227.

44. ACI Committee 209, "Prediction of Creep, Shrinkage and Temperature Effects in Concrete Structures," Designing for Effects of Creep, Shrinkage and Temperature in Concrete Structures, SP-27, American Concrete Institute, Farmington Hills, MI, 1971 (Reapproved 2008), pp. 51-93.

45. ACI Committee 209, "Guide for Modeling and Calculating Shrinkage and Creep in Hardened Concrete (ACI 209.2R-08)," American Concrete Institute, Farmington Hills, MI, 2008, 45 pp.

46. SOFiSTiK AG, "AQB Design of Cross Sections and of Prestressed Concrete and Composite Cross Sections v13.64," Software Manual, 2010.

47. SCIA, "SCIA Engineer. Reference Guide v2010.1," Software Manual, 2010, www.scia-online.com. (last accessed Apr. 26, 2011)

48. Infograph GmbH, "InfoCAD 10.4 Manual," Software Manual, 2010, www.infograph.eu. (last accessed Apr. 26, 2011)

49. Dlubal Engineering Software, "RSTAB 7. Structural Analysis for General Frameworks. Program Description," Software Manual, 1999, www.dlubal.com. (last accessed Apr. 26, 2011)

50. Trost, H., "Auswirkungen des Superpositionsprinzip auf Kriech- und Relaxations-Probleme bei Beton und Spannbeton," Beton- und Stahlbetonbau, V. 62, 1967, pp. 230-238, 261-269.

51. Bažant, Z. P., "Prediction of Concrete Creep Effects Using AgeAdjusted Effective Modulus Method," ACI Journal, Proceedings V. 69, No. 4, Apr. 1972, pp. 212-217.

52. Bažant, Z. P., and Najjar, L. J., "Comparison of Approximate Linear Methods for Concrete Creep," Journal of the Structural Division, ASCE, V. 99, No. ST9, 1973, pp. 1851-1874.

53. Burgoyne, C., and Scantlebury, R., "Why Did Palau Bridge Collapse?" The Structural Engineer, 2006, pp. 30-37.

54. CEB-FIP Model Code, Model Code for Concrete Structures, Comité euro-international du béton (CEB), Bulletin d'Information No. 213 and 214, Lausanne, Switzerland, 1990, 437 pp.
55. Bažant, Z. P., "Numerical Determination of Long-Range Stress History from Strain History in Concrete," Materials and Structures, V. 5, 1972, pp. 135-141.

\section{APPENDIX-PRESTRESSING STEEL RELAXATION AT VARIABLE STRAIN AND TEMPERATURE}

In Eq. (17), developed in Bažant and $\mathrm{Yu}^{40}{ }^{40}$ the viscoplastic strain is defined by

$$
\begin{gathered}
A_{T}=e^{\left(1 / T_{0}-1 / T\right) Q / k_{B}} \\
f\left(\varepsilon, \sigma_{p}\right)=k \rho^{1 / k} c^{(1-1 / k)} \frac{\left(F(\varepsilon)-\gamma f_{y}^{\prime}\right)}{E_{t}} \frac{\left(\varsigma^{1 / c}-1\right)^{(1-1 / k)}}{\lambda \varsigma^{(1+1 / c)}}
\end{gathered}
$$

where

$$
\varsigma=\frac{F(\varepsilon)-\gamma f_{y}^{\prime}}{\sigma_{p}-\gamma f_{y}^{\prime}}, \quad \rho=\rho_{0} e^{h \xi}
$$

Herein, $k, c, \rho_{0}$, and $h$ are positive empirical constants for the given steel; and $\rho_{0}$ is an empirical function of $\varepsilon(t)$. For oiltempered wire (OT Series in Magura et al. ${ }^{41}$ ), $\rho_{0}=0.34$ and $h=0.01$. At constant strain, $F(\varepsilon)=\sigma_{0}=$ initial prestress; $T(t)$ is absolute temperature; $T_{0}=298 \mathrm{~K}$; and $Q / k_{B} \approx 14,600 \mathrm{~K}^{43}$ $\left(k_{B}=\right.$ Boltzmann constant). Furthermore, $E_{t}=$ tangential modulus = initial $E$-modulus if the prestress is within linear range; $\sigma_{p}=F(\varepsilon)=$ short-time stress-strain curve and, for linear range, $F(\varepsilon)=E \varepsilon ; f_{y}^{\prime}$ is the yield strength (1\% offset); $\gamma f_{y}^{\prime}$ is the threshold below which there is no relaxation (safely $\gamma=0.45$, although often $\gamma=0.55$ ); $\xi=F(\varepsilon) / f_{y}^{\prime}-\gamma$; $k, c$ are the empirical exponents ${ }^{40}$; and the initial relaxation curve $\sigma_{0}-\sigma \propto t^{k}(k=0.08$, but the CEB Model Code gives different values for different steels; $c \approx 2$ ). 
